\title{
Hydrodynamic Model with Wave-Current Interaction in Coastal Regions
}

\author{
Hong Zhang ${ }^{*}$, Ole S. Madsen ${ }^{++}$, S. A. Sannasiraj ${ }^{+}$and Eng Soon $\mathrm{Chan}^{+}$ \\ * School of Engineering, Griffith University, Gold Coast Campus, PMB 50 \\ Gold Coast Mail Centre 9726, Australia, Email: hong.zhang@griffith.edu.au \\ ${ }^{++}$R. M. Parsons Laboratory, 48-216C, MIT, Cambridge, MA 02139, USA, Email: osm@mit.edu \\ +'12A Kent Ridge Rd., Tropical Marine Science Institute, National University of Singapore \\ Singapore 119223, Email: tmssas@nus.edu.sg, tmsdir@nus.edu.sg
}

\begin{abstract}
:
The effects of wave-current interaction on the hydrodynamics in coastal regions are investigated. A modified Grant-Madsen analytical model is incorporated into the Princeton Ocean Model (POM) to describe the wave-current interaction. The model is applied to the Singapore Straits for the prediction of tide and wind driven circulation. The simulation results confirm that high shear velocity within the wave bottom boundary layer produces high levels of turbulence intensities. The strong turbulence intensities within the thin wave bottom boundary layer in turn affect the currents through increased bottom resistance.
\end{abstract}

Key words: wave-current interaction, bottom roughness, hydrodynamic model, Singapore Strait

\section{Introduction}

A better understanding of the near-bottom physical processes is essential for the study of physical, chemical and biological processes in scientific and practical applications, including the erosion and transport of sediments near the seabed. To model the bottom layer, a drag law is often applied to represent the turbulent frictional processes. A linear bottom friction law has been utilized in earlier layered ocean models (e.g. Nowlin, 1967; Creegan, 1976). In more recent years, the nonlinear form of the bottom stress $\tau_{b}=\rho C_{d}\left|U_{r}\right| U_{r}$ is applied, where $C_{d}$ is the drag coefficient and $U_{r}$ is the reference velocity. In many studies, a constant $C_{d}$ has been adopted. For example, $C_{d}$ was taken to be 0.0025 in Backhaus \& Maier-Reimer (1983) and Soetje \& Brockmann (1983). Furnes (1980) suggested a value of 0.005 . The drag coefficients are typically determined during the calibration of models, through the comparison of computed and observed tidal currents. 
In Blumberg \& Mellor (1987), the bottom roughness is specified as a constant and the bottom stress is described using the log-profile of the law of the wall.

Near the sea bottom, there exist enhanced levels of turbulence due to wind wave activities (Grant \& Madsen, 1979; Mathisen \& Madsen, 1996; Mathisen \& Madsen, 1999). In particular, the short-period oscillatory nature of wave orbital velocity leads to a thin boundary layer above the bottom. In this wave bottom boundary layer, the fluid velocity changes from its free stream value to zero at the bottom, where the no-slip condition applies. The high shear velocity within the wave bottom boundary layer produces high levels of turbulence intensities and large bottom shear stresses. In shallow coastal waters, the near-bottom flow consists of waves and slowly varying currents. The strong turbulence intensities within the thin wave bottom boundary layer therefore have an impact on the currents, especially in causing the currents to experience an increased bottom resistance in the presence of waves.

Using the wave-current interaction model proposed by Grant \& Madsen (1979), Ningsih et al. (2000) and Xie et al. (2001) have shown that the surface waves could significantly affect the currents by modifying the bottom drag coefficient. However, experimental results (Mathisen \& Madsen, 1996) have shown that the apparent hydraulic roughness has been under-predicted by the Grant \& Madsen model (1979). A modified model, proposed by Mathisen and Madsen (1999), yielded a much better predictions of the roughness when compared with measurements.

It is clear that the influence of the wave-current interaction on the bottom stress is important in the modeling of mixing and sediment transport processes, especially in relatively shallow environments where the wave effects are felt at the sea bottom. In the present study, the modified Grant-Madsen analytical model for wave-current interaction, which produces values of the bottom roughness experienced by a current from the knowledge of wind-wave, current bottom shear stress as well as bottom sediment characteristics, is incorporated in a three dimensional hydrodynamic model. The influence of the wave-current interaction is examined for typical scenarios of wind-current-tide driven circulations in the Singapore Straits. 


\section{Mathematical Model}

\subsection{Hydrodynamics}

The flow equations governing ocean circulation consist of the hydrostatic, the Boussinesq Navier-Stokes equations along with equations for turbulent kinetic energy (Mellor, 1998). The hydrostatic assumption and the Boussinesq approximation are commonly used in ocean circulation modelling based on the premise that the horizontal extent is much larger than the vertical extent. The governing equations thus formulated in orthogonal Cartesian coordinates with $x$ increasing in the eastward direction, $y$ increasing in the northward direction and $\mathrm{z}$ vertically positive upwards from an undisturbed mean water level are summarized as follows.

(a) The continuity equation,

$$
\nabla \cdot U+\frac{\partial w}{\partial z}=0
$$

where $U$ is the horizontal velocity vector having components $(u, v)$ and $w$ is the vertical components of the velocity, and $\nabla=\left(\frac{\partial}{\partial x}, \frac{\partial}{\partial y}\right)$ is the horizontal gradient operator.

(b) The Reynolds momentum equations,

$$
\begin{aligned}
& \frac{\partial u}{\partial t}+U \cdot \nabla u+w \frac{\partial u}{\partial z}-f v=-\frac{1}{\rho_{0}} \frac{\partial P}{\partial x}+\frac{\partial}{\partial z}\left(K_{M} \frac{\partial u}{\partial z}\right)+F_{x} \\
& \frac{\partial v}{\partial t}+U \cdot \nabla v+w \frac{\partial v}{\partial z}+f u=-\frac{1}{\rho_{0}} \frac{\partial P}{\partial y}+\frac{\partial}{\partial z}\left(K_{M} \frac{\partial v}{\partial z}\right)+F_{y} \\
& \rho g=-\frac{\partial P}{\partial z}
\end{aligned}
$$

where $\rho_{0}$ is the reference density; $\rho$ is the local density; $g$ is the gravitational acceleration; $P$ is the pressure; $K_{\mathrm{M}}$ is the vertical eddy diffusivity of turbulent momentum; $f$ is the Coriolis parameter, and $\left(F_{\mathrm{x}}, F_{\mathrm{y}}\right)$ are general forcing terms, e.g. accounting for lateral mixing.

(c) To characterize turbulence, it has been assumed that turbulent kinetic energy $\left(q^{2 / 2}\right)$ and macroscale $(l)$ are subjected to transport history effects. In this way, a so-called twoequation model can be established to determine the transport of these quantities. Mellor \& 
Yamada (1982) proposed a turbulence closure scheme based on the Rotta-Kolmogorov model (Mellor \& Herring, 1973). This scheme is reported in detail by Blumberg \& Mellor (1987). In the horizontal direction, the mixing terms, $F_{x}, F_{y}$ in equations (2), are parameterized using the concept of turbulent diffusion in analogy to molecular diffusion. These terms are defined as,

$$
\begin{aligned}
& F_{x}=\frac{\partial}{\partial x}\left[2 A_{M} \frac{\partial u}{\partial x}\right]+\frac{\partial}{\partial y}\left[A_{M}\left(\frac{\partial u}{\partial y}+\frac{\partial v}{\partial x}\right)\right] \\
& F_{y}=\frac{\partial}{\partial y}\left[2 A_{M} \frac{\partial v}{\partial y}\right]+\frac{\partial}{\partial x}\left[A_{M}\left(\frac{\partial u}{\partial y}+\frac{\partial v}{\partial x}\right)\right]
\end{aligned}
$$

where the horizontal diffusivity $A M$ is determined using the Smagorinsky formula (Blumberg \& Mellor, 1987) as a function of fluid velocity and grid sizes.

\subsection{Conceptual bottom boundary}

Within the constant stress layer, immediately above the bottom, the law of the wall is assumed and leads to the classic logarithmic profile

$U=\frac{U_{*}}{\kappa} \ln \frac{z}{Z_{0 b}}$,

with $Z_{0 b}$, a reference location where $U=0, U_{*}$, the shear velocity, and $\kappa$ is von Karman's constant. Equation (5) is only valid for the region immediately above the bottom, or as a limiting behavior as $z \rightarrow Z_{0 b}$. If $z=z_{r}$ is close enough to the bottom to be considered within the constant stress layer, the concept of a bottom friction factor can be defined by

$$
\tau_{b}=\rho C_{z_{r}}\left|U_{r}\right| U_{r},
$$

where $U_{r}$ is the reference velocity used in the "drag-law formulation", i.e. $U_{r}=U\left(z_{r}\right)$, and $C_{z_{r}}$ is the bottom drag coefficient referenced to $U$ at $z=z_{r}$.

If $z_{r}$ falls within the constant stress layer, (5) can be used to evaluate $U\left(z_{r}\right)$ in equation (6), and the bottom friction coefficient can be expressed using the shear velocity definition as follows, 
$C_{z_{r}}=\left[\kappa / \ln \frac{z_{r}}{Z_{0 b}}\right]^{2}$

where $Z_{0 b}$, for combined wave-current boundary layers is related to the apparent bottom roughness, $k_{N A}$, e.g. $k_{N A}=30 Z_{0 b}$, for fully rough turbulent flow.

The bottom stress is determined from the quadratic drag law applied at the point closest to the bed where there is a velocity estimate. Because the distance between the lowest velocity point and the bed varies with location, the bottom roughness length is specified at each location, and then a constant stress layer is assumed so that an effective drag coefficient can be computed at the velocity point.

Based on skin friction, the Shields Parameter, $\psi_{m}^{\prime}$ can be calculated following the model presented by Madsen (2002),

$\Psi_{m}^{\prime}=\frac{U_{* w m}^{\prime}{ }^{2}}{(s-1) g d}$

with

$U_{* w m}^{\prime}{ }^{2}=\frac{1}{2} f_{w}^{\prime} U_{b m}{ }^{2}$ and $f_{w}^{\prime}=\exp \left\{5.61\left(\frac{U_{b m}}{d \omega_{r}}\right)^{-0.109}-7.30\right\}$,

where $d$ is sediment diameter and $\mathrm{s}$ is the ratio of density of sediment to density of water; $U_{b m}$ is the amplitude of the equivalent periodic wave near-bottom orbital velocity; and $U_{*_{w m}}$ is the maximum friction velocity due to wind-waves. It is clear that the bottom roughness is related to a number of bed attributes including sand grains, wave-formed ripples and, for extreme flow conditions, a highly concentrated near-bed sheet flow sediment transport layer. In past studies, various bottom roughness models have been presented, including Grant \& Madsen (1982), Nielsen (1992) and Sorenson et al. (1995). Generally, in the absence of wave-formed ripples, sand grains are considered the dominant roughness elements and the movable bed roughness is proportional to $d$ (Engelund \& Hansen, 1972; Van Rijn, 1984). However, for most coastal flows, where waves are present, ripples are formed on the bottom. These ripples are several orders of magnitude larger in height than the sand grain diameter and the ripples usually scale the 
bottom roughness on wave-dominated shelves. In the present study, Madsen's (2002) model for movable bed roughness is applied. The movable bed roughness can then be evaluated by the following conditions:

$$
\begin{aligned}
& k_{N}=d \quad \text { for } \quad \Psi_{m}^{\prime}<\frac{\Psi_{c r}}{2} \\
& k_{N}=4 \frac{U_{b m}}{\omega_{r}} \times\left\{\begin{array}{lll}
1.8 \times 10^{-2} Z^{-0.5} & \text { for } & Z<0.012 \\
7.0 \times 10^{-4} Z^{-1.23} & \text { for } & 0.012<Z<0.18
\end{array}\right. \\
& k_{N}=15 \Psi_{m}^{\prime} d \quad \text { for } Z>0.18 \text { or } \Psi_{m}^{\prime}>0.35
\end{aligned}
$$

where $\Psi_{c r}$, the critical value of Shields Parameter for initiation of sediment motion, is obtained as a function of the fluid-sediment parameter $S_{*}=\frac{d}{4 v} \sqrt{(s-1) g d}$ from the modified Shields Diagram (Madsen \& Grant 1976) and its extension (Madsen, 2002), and $Z=\Psi_{m}^{\prime} / S_{*} ; v$ is the fluid viscosity.

If $\Psi_{m}^{\prime}<\frac{\Psi_{c r}}{2}$, there is no sediment motion and the physical bottom roughness $k_{N}$ equals the sediment diameter, $d$. When $\Psi_{m}^{\prime}>\frac{\Psi_{c r}}{2}$, sediment motion occurs and the bottom is rippled until, for $\Psi_{m}^{\prime}>0.35$, the bottom becomes flat with sheet flow.

\subsection{Wave specification near seabed}

The near-bottom wave velocity and bottom shear stress may be expressed in terms of the directional surface wave spectrum. A state-of-the-art wind-wave model typically outputs wind-wave characteristics in the form of their directional frequency surface spectrum $S_{\eta \eta}(\omega, \phi)$, where $\omega$ is the radian frequency and $\phi$ is direction of propagation from the x-axis. The near-bottom velocity directional spectrum is obtained from linear theory by use of the transformation (Madsen, 1995),

$S_{U_{b} U_{b}}(\omega, \phi)=\left(\frac{\omega}{\sinh k D}\right)^{2} S_{\eta \eta}(\omega, \phi)$,

where $D=H+\eta$ is total mean depth and $k$ is the wave number, which is obtained for each frequency by solving the dispersion relationship $\omega^{2}=k g \tanh k D$. From (11) the equivalent 
periodic wave near-bottom orbital velocity amplitude $U_{b m}$, radian frequency $\omega_{r}$, and the dominant direction from the $\mathrm{x}$-axis (positive in the counter-clockwise direction) can be written as (Madsen, 1995),

$U_{b m}=\left[2 \iint S_{U_{b} U_{b}}(\omega, \phi) d \omega d \phi\right]^{\frac{1}{2}}$

$\omega_{r}=\frac{\iint \omega S_{U_{b} U_{b}}(\omega, \phi) d \omega d \phi}{\iint S_{U_{b} U_{b}}(\omega, \phi) d \omega d \phi}$

and

$\tan \phi_{w}=\frac{\iint \sin \phi S_{U_{b} U_{b}}(\omega, \phi) d \omega d \phi}{\iint \cos \phi S_{U_{b} U_{b}}(\omega, \phi) d \omega d \phi}$.

\subsection{Wave-Current interaction}

Following Madsen (1995), the bottom shear stress vector can be calculated from (6)

$\left\{\tau_{b x}, \tau_{b y}\right\}=\rho C_{z_{r}}\left(u_{r}^{2}+v_{r}^{2}\right)^{\frac{1}{2}}\left\{u_{r}, v_{r}\right\}$,

with $C_{z_{r}}$ defined by (7). In the presence of waves, the wave-current interaction theory by Madsen (1995), as modified by Mathisen and Madsen (1999), is applied to compute the value of the apparent roughness, $k_{N A}=30 Z_{0 b}$, i.e. the bottom roughness experienced by the current in the presence of waves.

The direction of the current $\phi_{c}$ can be obtained as $\tan \phi_{c}=\frac{\tau_{b y}}{\tau_{b x}}$, and the total magnitude of

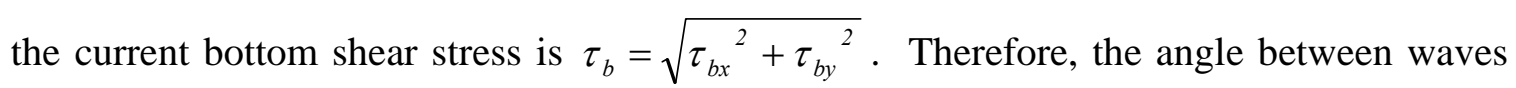
and current $\phi_{w c}$ is defined as $\phi_{c}-\phi_{w}$.

The maximum wave bottom shear stress can be obtained from

$\tau_{w m}=\frac{1}{2} \rho_{w} f_{w c} U_{b m}^{2}$ 
where the combined wave-current friction factor, $f_{w c}$, is a function of the relative strength of currents and waves, specified by

$$
\begin{aligned}
& \mu=\frac{\tau_{b}}{\tau_{w m}} \\
& C_{\mu}=\left\{1+2 \mu\left|\cos \phi_{w c}\right|+\mu^{2}\right\}^{\frac{1}{2}} .
\end{aligned}
$$

and is given by

$$
f_{w c}=C_{\mu} \exp \left\{5.61\left(\frac{C_{\mu} U_{b m}}{k_{n} \omega_{r}}\right)^{-0.109}-7.30\right\} .
$$

Equations (16) through (18) are solved iteratively, by first assuming $\mu=0$ and $C_{\mu}=1$ to obtain an initial estimate of $\tau_{w m}$ from equations (18) and (16). With this value of $\tau_{w m}$, $\mu$ and $C_{\mu}$ are updated using equation (17) and the procedure is repeated till convergence of $\mu$ is obtained with two significant digits.

Then, the wave boundary layer thickness is given as

$$
\delta_{w c}=A \kappa \frac{\sqrt{\frac{C_{\mu} \tau_{w m}}{\rho}}}{\omega_{r}},
$$

using the final values for $C_{\mu}$ and $\tau_{w m}, \kappa=0.4$ and the scaling factor, introduced by Mathisen and Madsen (1999),

$$
A=\exp \left\{2.96\left(\frac{C_{\mu} U_{b m}}{k_{N} \omega_{r}}\right)^{-0.071}-1.45\right\} .
$$

Finally, the apparent roughness, $k_{N A}=30 Z_{0 b}$, is obtained by solving the equation

$$
\frac{\frac{\tau_{b}}{\rho}}{\kappa \sqrt{\frac{C_{\mu} \tau_{w m}}{\rho}}} \ln \left(\frac{\delta_{w c}}{\frac{k_{N}}{30}}\right)=\frac{\sqrt{\frac{\tau_{b}}{\rho}}}{\kappa} \ln \frac{\delta_{w c}}{Z_{0 b}},
$$

or, 
$Z_{0 b}=\delta_{w c}\left[\frac{30 \delta_{w c}}{k_{N}}\right]^{-\sqrt{\frac{\tau_{b}}{C_{\mu} \tau_{w m}}}}$.

In which $k_{N}$ is the physical bottom roughness obtained from (10). From the above procedure, the corresponding value of bottom friction coefficient $C_{z_{r}}$ can be updated by use of (7).

\section{Case study in the Singapore Straits}

The modified Grant-Madsen analytical model for combined wave-current bottom boundary layers is applied, as described in the preceding section, to the Straits of Singapore, and evaluated by comparing simulated results with observed data. The model domain covers the entire Singapore and its surrounding shallow shelf waters. It extends from $0^{\circ} 59^{\prime} \mathrm{N}$ to $1^{\circ} 44^{\prime} \mathrm{N}$ in latitude and from $103^{\circ} 18^{\prime}$ to $104^{\circ} 20^{\prime}$ in longitude. The bathymetry and locations of the measurement stations are shown in Fig. 1. The model has a uniform horizontal resolution of $1 \mathrm{~km}$ in latitude and longitude and a vertical resolution of 15 sigma layers.

A typical Singapore Straits flow field is simulated using a period of 14 days from $0000 \mathrm{hr}$ 01/03/2001 to $0000 \mathrm{hr} 15 / 03 / 2001$. To validate the model, statistic error analysis techniques are applied. The efficiency of the prediction is examined in terms of the root mean square error (RMSE) and the correlation coefficient $(\gamma)$.

The optimal value of the bottom roughness length $Z_{0 b}$ for the erosion and bedload regimes was determined to be $0.01 \mathrm{~m}$ by Kikuchi et al. (1999) and Signell et al. (2000). For the hydrodynamic simulation in the same region, Chen \& Chan (1997) have also specified $Z_{0 b}$ $=0.01 \mathrm{~m}$ and their results were verified with measured data. Since the spatial variability of $Z_{0 b}$ could not be determined from the data, $Z_{0 b}=0.01 \mathrm{~m}$ was used throughout the domain without explicitly accounting for the presence of waves. Tidal elevation simulations at Tuas $\left(1^{\circ} 17^{\prime} \mathrm{N}, 103^{\circ} 40 \mathrm{E}\right)$, and Raffles Light House $\left(1^{\circ} 10^{\prime} \mathrm{N}, 103^{\circ} 44{ }^{\prime} \mathrm{N}\right)$ were compared with observed values and showed good agreement at both stations, with correlation coefficients $\gamma=0.99$. 
When waves are taken into account, the wave generation in the domain is simulated using a third generation wave model WAM (The WAMDI group, 1988). In the Singapore Straits, the Northeast monsoon wind is dominant during March, and hence this wind condition is applied to drive the wave model. For the purpose of gauging the influence of wave-current interactions, the wind speed is assumed to be $10 \mathrm{~m} / \mathrm{s}$. The steady state wave parameters, including the wave height and the radian frequency, are evaluated. At the southwest region, the highest wave can reach up to $1 \mathrm{~m}$. The radian frequency is low at the eastern opening, but high at the southeast and southwest openings. These wave parameters are used in the hydrodynamic model for the upgrading of the bottom roughness. In the shallow water of the southwest region, values of $U_{b m}$ are large with a peak value of $0.8 \mathrm{~m} / \mathrm{s}$. The typical sediment particle diameter of $d=0.2 \mathrm{~mm}$ is assumed for the entire domain. The movable bed roughness, $k_{N}$, can then be calculated by using equations (8)-(11) based on the wave parameters. The distribution of $k_{N}$ is shown in Fig. 2(a). Generally, the distribution of $k_{N}$ reflects the distribution of $U_{b m}$ and $\omega_{r}$. In a small region in the eastern part of the Singapore Strait, the computed movable bottom roughness reaches up to $0.2 \mathrm{~m}$ since $U_{b m}$ is relatively high at $0.16 \mathrm{~m} / \mathrm{s}$ (where the water depth is shallow around $30 \mathrm{~m}$ ) and the radian frequency is low at about $0.4 \mathrm{rad} / \mathrm{s}$. The $Z$ used in equation (10) is greater than 0.012, which leads to a strongly rippled bed with $k_{N}$ about $0.2 \mathrm{~m}$. The large bottom velocity $U_{b m}$ enhances the turbulence resulting in increasing the bottom roughness and retarding the bottom flow. However, in most of the eastern region, the wave effect is insignificant. In general, it is found that $U_{b m}$ increases with increasing wave height and decreasing frequency and water depth, but it is more sensitive to the water depth and radian frequency than to the wave height.

By comparing RMSE for water elevation simulations with and without wave-current interactions at the various measurement stations, it is noted that the influence of wavecurrent interaction on the surface elevation is trivial, but its effect on the current velocity is of more significance as shown in Fig. 3. As discussed earlier, the bottom friction in deep waters is a term in the governing equations that is of minor importance; most of the force balance is achieved by balancing hydrostatic pressure gradient and fluid acceleration. For a given significant wave height and wave period, the bottom orbital 
velocity increases with decreasing water depth, causing an enhanced bottom friction coefficient. The vertical extent of wave-associated turbulence is limited by the wave boundary layer. The wave contribution to the turbulent mixing must decrease with the distance away from the bottom. Near the surface only the current shear velocity contributes to the turbulent mixing. Fig. 3 shows the near-bottom velocity at $0.126 \mathrm{~m}$ above the bottom for Gusong Beacon Station. It is evident that wave effects on the nearbottom current velocity are much more significant than in the upper layers. The higher turbulence intensities near the bottom leads to a lower current velocity, but the relative directions of wave and current flows do not have a pronounced influence on the wavecurrent interaction. It should be noted that near-bottom turbulent eddy viscosity, $K_{M^{\sim}}$ $\kappa U_{*}$, increases with increasing shear stress. The influence on sediment transport and the mixing of other substances is significant near the sea bottom. As current measurements in shallower water are not available, Table 1 list the comparison of computed depthaveraged velocity with and without the wave effects at a few selected locations in shallow water as marked in Fig. 1. It is evident that the current is retarded in the presence of waves and that wave effects not only influence the near-bottom velocities but the entire water column as well in shallow areas. This suggests that tidal current measurements obtained for model calibration should include the shallow areas, especially if one is concerned with the modeling of bottom shear stress.

Fig. 2(b) shows the distribution of apparent bottom roughness $k_{N A}$, where $k_{N A}=30 Z_{0 b}$, in the whole domain at $t=3$ days. It is clear that the distribution of $k_{N A}$ is analogous to that of the movable bottom roughness, $k_{N}$, shown in Fig. 2(a). In most of the eastern region, the bottom roughness is small and not significantly affected by wave-current interaction. However, in a small region near $(1.2 N, 104.2 E)$, both $k_{N A}$ and $k_{N}$ are relatively larger. These results reinforce the earlier conclusion that currents in the presence of waves experience an enhanced bottom roughness. Simulations also show that the near- bottom flow velocities are generally reduced. The effect of wave-current interaction on the flow pattern would affect the transport of sediment and other near-bottom environmental transport process. 


\section{Conclusions}

In this study, a modified Grant-Madsen analytical mode for wave-current interaction has been incorporated into the Princeton Ocean Model. The values of the bottom roughness experienced by a current are produced from the knowledge of wind-wave characteristics, current bottom shear stress and bottom sediment characteristics.

Typical wave-current interaction effects on tidal currents for the Singapore Straits were examined. In this application, realistic near-bottom wave orbital velocity spectra were simulated and the high velocity shear within the wave bottom boundary layer produces high levels of turbulence intensities and results in large bottom stresses experienced by the currents. The significance of wave-current interaction depends mainly on the water depth and the current experiences an increased bottom resistance in the presence of waves in shallow waters with high wind-wave activity. Whereas the improvement in surface elevation predictions is trivial (in the range of 1.7\% - 3.7\% at three different locations) the results confirm that the apparent bottom roughness affects the near-bottom velocity field significantly in shallow water with high wave activity.

Accounting for wind-wave effects in a three-dimensional hydrodynamics model improves predictions of currents in shallow coastal waters. Wave effects are important in shallow near-shore regions where wave-current interaction depends upon wave heights, wave development status and wave-generated bed-form types. This suggests that good wave prediction and details of bed-form types in near-shore waters are necessary for an accurate prediction of slowly varying currents. In this study, the influence of wave-current was only examined for its effects on the hydrodynamics. A further study, using the calculated velocity and eddy diffusivities, to simulate the sediment transport and the trajectory of water particles to obtain a better prediction of the ocean environment is ongoing. 


\section{Reference:}

Backhaus, J.O. \& Maier-Reimer, E. 1983 On Seasonal Circulation in the North Sea. North Sea Dynamics, pp. 63, Springer-Verlag.

Blumberg, A. F. \& Mellor, G. L. 1987 A description of a three-dimensional coastal model. In: N. Heaps (ed.), Three-Dimensional Coastal Ocean Models. Washington D.C.: American Geophysical Union, Coastal and Estuarine Sciences, Series Number 4, 1-16.

Chen, M. \& Chan, E. S. 1997 Three dimensional circulation model of Singapore coastal waters, Proceeding of Oceanology International 97, Singapore, 12-14 May 1997, 281291.

Creegan, A. 1976 A numerical investigation of the circulation in the Norwegian Sea, Tellus 28, pp. 451.

Engelund, F., \& Hansen, E. 1972 A Monograph on Sediment Transport in Alluvial Streams, 3rd. ed., Tech. Press, Copenhagen.

Furnes, G. K. 1980 Wind effects in the North Sea. Journal of Physical Oceanography, 10, pp978.

Grant, W. D. \& Madsen, O. S. 1979 Combined wave and current interaction with a rough bottom. Journal of Geophysical Research, 84, 1797-1808.

Grant, W.D. \& Madsen, O.S. 1982 Movable bed roughness in unsteady oscillatory flow. Journal of Geophysical Research, 87, 469-481.

Kikuchi, T., Wakatsuchi, M. \& Ikeda, M. 1999 A numerical investigation of the transport process of dense shelf water from a continental shelf to a slope. Journal of Geophysical Research, 104(C1), 1197-1210.

Madsen, O.S. 1995 Spectral wave-current bottom boundary layer flows. Proc. 24th ICCE. ASCE, 1:384-398.

Madsen, O. S. 2002 Sediment Transport Outside the Surf Zone. In: Walton, T. (editor), Coastal Engineering Manual, Part III Coastal Processes, Engineer Manual 1110-21100, U.S. Army Corps of Engineers, Washington D.C.

Madsen, O.S. \& Grant, W. D. 1976 Quantitative description of sediment transport by waves. Proceedings $15^{\text {th }}$ International Coastal Engineering Conference, ASCE, Vol 2, pp1093-1112.

Mathisen, P.P. \& Madsen, O. S. 1996 Waves and currents over a fixed rippled bed: I. Bottom roughness experienced by waves and II. Bottom and apparent roughness experienced by currents. Journal of Geophysical Research, 101(C7), 533-16,550.

Mathisen, P.P. \& Madsen, O.S. 1999 Waves and currents over a fixed rippled bed: III. Bottom and apparent roughness for spectral waves and currents. Journal of Geophysical Research, 104(C8): 18447-18461.

Mellor, G.L. 1998 User Guide for a three-dimensional, primitive equation, numerical ocean model (53 pp). 
Mellor, G.L. \& Herring, H. J. 1973 A survey of the mean turbulent field closure models, AIAA Journal, 11, 590-599.

Mellor, G.L. \& Yamada, T. 1982 Development of a turbulence closure model for geophysical fluid problems. Reviews of Geophysics, 20, 851-875.

Nielsen, P. 1992: Coastal Bottom Boundary Layers and Sediment Transport. World Scientific (324 pp).

Ningsih, N.S., Yamashita, T. \& Aouf, L. 2000 Three-dimensional simulation of water circulation in the Java Sea: Influence of wind waves on surface and bottom stress. Natural Hazards, 21: 145-17.

Nowlin, W. D. 1967 A steady, wind-driven, friction model of two moving layers in a rectangular ocean basin. Deep Sea Research, 14, 89.

Signell, R. P., List, J. H., \& Farris, A. S. 2000 Bottom Currents and Sediment Transport in Long Island Sound: A Modeling Study. Journal of Coastal Research, Vol. 16, pp. 551566.

Soetje, K.C. \& Brockmann, C. 1983 An Operational Numerical Model of the North Sea and the German Bight. North Sea Dynamics, (pp. 95), Springer-Verlag.

Sorenson, K. S., Madsen, O. S. \& Wright, L. D. 1995 Evidence of directional dependence of moveable bottom roughness in inner shelf waters. EOS Supplement, November, pp.F281.

The WAMDI Group 1988 The WAM model - A third generation ocean wave prediction model. Journal of Physical Oceanography, 18, 1775-1810.

Van Rijn, L.C. 1984 Sediment transport. Part III: Bed forms and alluvial roughness, Journal of Hydraulic Engineering, ASCE 110(12), 1733-1754.

Xie L., Wu, K., Pietrafesa, L. \& Zhang, C. 2001 A numerical study of wave-current interaction through surface and bottom stress Part I: Wind-driven circulation in the South Atlantic Bight under uniform winds. Journal of Geophysical Research, 106, 16841-16856. 
Fig. 1. The bathymetry for the Singapore Straits application domain and the locations of observation stations. (The grey scale bar indicates the water depth in meter.)

Fig. 2. (a) The typical distribution of movable bed roughness, $k_{N}$, in March. (b) The distribution of bottom roughness, $k_{N A}$, at time $t=3$ day. (The grey scale bars indicate the roughness in meter.)

Fig. 3. Comparison of the velocity at Gusong Beacon Station at depth of $0.126 \mathrm{~m}$ above bottom. 
Table 1. Comparison of the simulated depth averaged velocities with and without wavecurrent interaction

\begin{tabular}{|c|c|c|c|}
\hline & depth $(\mathrm{m})$ & $\begin{array}{c}U_{a}(\mathrm{~m} / \mathrm{s}) \\
\text { no wave }\end{array}$ & $\begin{array}{c}U_{a}(\mathrm{~m} / \mathrm{s}) \\
\text { with wave }\end{array}$ \\
\hline location 1 & 8 & -0.67 & -0.62 \\
\hline location 2 & 9 & -0.62 & -0.58 \\
\hline location 3 & 18 & -0.89 & -0.86 \\
\hline location 4 & 19 & -0.84 & -0.80 \\
\hline
\end{tabular}

